\title{
$\beta$-catenin signaling pathway regulates cisplatin resistance in lung adenocarcinoma cells by upregulating Bcl-xl
}

\author{
JIN ZHANG ${ }^{1}, \mathrm{JIE} \mathrm{LIU}^{2}, \mathrm{HUI} \mathrm{LI}^{3}$ and JUN WANG ${ }^{2}$ \\ ${ }^{1}$ Department of Surgical Intensive Care Unit, Beijing Chao-Yang Hospital, Capital Medical University, \\ Beijing 100020; ${ }^{2}$ Department of Physiology, Capital Medical University, Beijing 100069; \\ ${ }^{3}$ Department of Thoracic Surgery, Beijing Chao-Yang Hospital, Capital Medical University, Beijing 100020, P.R. China
}

Received May 4, 2015; Accepted January 6, 2016

DOI: $10.3892 / \mathrm{mmr} .2016 .4882$

\begin{abstract}
The Wnt/ $\beta$-catenin signaling pathway has been reported to regulate cisplatin resistance in several types of cancer cell. The present study aimed to investigate the role and underlying mechanism of $\mathrm{Wnt} / \beta$-catenin signaling in cisplatin resistance of lung adenocarcinoma cells. Wild-type and cisplatin-resistant A549 human lung adenocarcinoma cells (A549/WT and A549/CDDP, respectively) were cultured in vitro and exposed to different cisplatin concentrations. Cells were incubated with $10 \mathrm{mM}$ lithium chloride $(\mathrm{LiCl})$ to activate $\beta$-catenin signaling. Cell proliferation was determined using the MTS assay. Cell apoptosis was evaluated using Annexin V/propidium iodide double staining, followed by flow cytometry. $\beta$-catenin was knocked down using small interfering RNA (siRNA). The intracellular distribution of $\beta$-catenin was determined by immunocytochemistry, and the mRNA and protein expressions of target genes were examined by reverse transcription-quantitative polymerase chain reaction and western blotting, respectively. $\beta$-catenin and B-cell lymphoma-extra large (Bcl-xl) were significantly upregulated in A549/CDDP cells compared with A549/WT cells $(\mathrm{P}<0.05)$. $\mathrm{LiCl}$ reduced the sensitivity of A549/WT cells to cisplatin $(\mathrm{P}<0.01)$; and upregulated, increased phosphorylation $(\mathrm{P}<0.05)$ and enhanced nuclear translocation of $\beta$-catenin. $\mathrm{LiCl}$ also significantly elevated the mRNA and protein expression levels of $\mathrm{Bcl}-\mathrm{xl}(\mathrm{P}<0.05)$. Notably, silencing of $\beta$-catenin with siRNA decreased the mRNA and protein expression of Bcl-xl, and sensitized A549/WT cells to cisplatin $(\mathrm{P}<0.01)$. The findings of the current study suggest that upregulation of
\end{abstract}

Correspondence to: Dr Hui Li, Department of Thoracic Surgery, Beijing Chao-Yang Hospital, Capital Medical University, 8 Baijiazhuang Road, Chaoyang, Beijing 100020, P.R. China

E-mail: huilee@vip.sina.com

Dr Jun Wang, Department of Physiology, Capital Medical University, 8 Xitoutiao, Youwai Street, Beijing 100069, P.R. China

E-mail: wang_jun@ccmu.edu.cn

Key words: lung adenocarcinoma cells, cisplatin resistance, $\beta$-catenin, B-cell lymphoma-extra large $\beta$-catenin signaling may contribute to cisplatin resistance in lung adenocarcinoma cells by upregulating Bcl-xl. Therefore, molecular targeting of $\mathrm{Wnt} / \beta$-catenin signaling may sensitize lung cancer cells to cisplatin.

\section{Introduction}

Lung cancer is the leading cause of cancer-associated mortality worldwide, with an age-standardized world incidence rate of 44.7 for males and 19.6 for females per 100,000, and an age-standardized world mortality rate of 36.8 for males and 14.3 for females per 100,000 in more developed areas (1). In the past decade, great advances have been made in the treatment of lung cancer using surgery, chemotherapy and radiotherapy; however, the five-year survival rate is still low (2). The majority of patients with cancer develop drug resistance later in later life resulting in metastatic cancer growth and, ultimately, mortality. Therefore, drug resistance is a major challenge in the treatment of lung cancer (3). It is imperative to elucidate the underlying mechanisms and identify novel strategies to overcome drug resistance.

Cisplatin, a platinum-containing anticancer drug, has been widely used for the treatment of various types of human cancer, including lung, bladder, ovarian, and head and neck cancer (4). Cisplatin is a potent chemotherapeutic agent, however, the development of cisplatin resistance is a major obstacle for the successful treatment of lung cancer. Cisplatin resistance in lung cancer may be a result of multiple mechanisms, including excessive drug accumulation inside cancer cells, drug inactivation, enhanced repair of DNA damage, as well as abnormal activation of cell signaling pathways via growth factors and cytokines (5). However, the precise molecular mechanisms of cisplatin resistance in lung cancer cells remains unclear.

Several studies have demonstrated the Wnt/ $\beta$-catenin signaling pathway to be important in cisplatin resistance of human malignancies $(6,7)$. $\beta$-catenin is highly expressed in cisplatin-resistant A549 human lung adenocarcinoma cells (A549/CDDP) (8). Furthermore, other recent studies demonstrated that deregulation of Wnt/ $\beta$-catenin signaling was closely associated with cisplatin resistance in lung cancer cells $(9,10)$; however, the underlying molecular mechanisms remain to be determined. Ding et al (11) demonstrated that $\beta$-catenin upregulates the expression of the anti-apoptotic protein B-cell 
lymphoma-extra large (Bcl-xl) in $\mathrm{CD} 4{ }^{+} \mathrm{CD} 25^{+}$regulatory $\mathrm{T}$ cells. Evasion of apoptosis is a hallmark of cancer cells and $\mathrm{Bcl}-\mathrm{xl}$ has an important role in the prevention of cell apoptosis. Furthermore, cisplatin induces DNA damage, which activates the apoptotic cascade, killing cancer cells. This suggests that the $\beta$-catenin signaling pathway may promote cisplatin resistance in lung cancer cells by enhancing the expression of Bcl-xl.

The present study examined the expression of $\beta$-catenin and Bcl-xl in wild-type (A549/WT) and A549/CDDP lung adenocarcinoma cells. In addition, the functional role of the Wnt/ $\beta$-catenin signaling pathway, and its association with $\mathrm{Bcl}-\mathrm{xl}$ expression, were investigated in cisplatin resistance of lung adenocarcinoma cells.

\section{Materials and methods}

Reagents. The following reagents were used in the present study: Fetal bovine serum (FBS), RPMI-1640 (Hyclone; GE Healthcare Life Sciences, Logan, UT, USA), lithium chloride (LiCl; Sigma-Aldrich, St. Louis, MO, USA), CellTiter 96 AQueous One Solution Cell Proliferation Assay (MTS assay; Promega Corporation, Madison, WI, USA) and FITC Annexin V (BD Biosciences, San Jose, CA, USA). Rabbit polyclonal anti- $\beta$-catenin (cat. no. sc-7199; 1:2,000 dilution; Santa Cruz Biotechnology, Inc., Dallas, TX, USA), mouse monoclonal anti- $\beta$-actin (cat. no. sc-130065; Santa Cruz Biotechnology, Inc.; 1:1,000 dilution), rabbit monoclonal anti-phosphorylated (p)- $\beta$-catenin (cat. no. 4176; 1:1,000 dilution; Cell Signaling Technology, Inc., Boston, MA, USA), rabbit monoclonal anti-Bcl-xl (cat. no. 2764; Cell Signaling Technology, Inc.; 1:1,000 dilution), horseradish peroxidase (HRP)-conjugated polyclonal goat anti-mouse IgG (cat. no. SA0001-1; 1:5,000 dilution; ProteinTech Group, Inc., Chicago, IL, USA) and goat anti-rabbit IgG (cat. no. SA0001-2; 1:5,000 dilution; ProteinTech Group, Inc.) antibodies were used for western blotting. Small interfering RNA (siRNA; Shanghai GenePharma Co., Shanghai, China) and Lipofectamine 2000 transfection reagent (Invitrogen; Thermo Fisher Scientific, Inc., Waltham, MA, USA) were also used.

Cell culture and drug treatment. A549/WT and A549/CDDP cells were obtained from the Chinese Academy of Medical Sciences (Beijing, China) and the Cancer Hospital of Peking Union Medical College, Chinese Academy of Medical Sciences (Beijing, China), respectively. Cells were cultured in RPMI-1640 culture medium supplemented with $10 \%$ FBS, $100 \mathrm{U} / \mathrm{ml}$ penicillin and $100 \mu \mathrm{g} / \mathrm{ml}$ streptomycin (GE Healthcare Life Sciences). A549/CDDP cells were grown in complete culture medium containing $2 \mathrm{mg} / \mathrm{l}$ cisplatin. Cell cultures were maintained in a $5 \% \mathrm{CO}_{2}$-humidified incubator at $37^{\circ} \mathrm{C}$. To activate $\beta$-catenin signaling, cells were incubated with $10 \mathrm{mM} \mathrm{LiCl}$ for 24 or $48 \mathrm{~h}$.

MTS assay. An MTS assay was used to determine the proliferative potential of cells. In brief, cells were seeded onto 96-well plates at a density of $5 \times 10^{3}$ cells/well. Following different treatments, $20 \mu \mathrm{l}$ of MTS solution was added to cells. After incubation for $1 \mathrm{~h}$ at $37^{\circ} \mathrm{C}$, the absorbance was measured at $490 \mathrm{~nm}$ using an Infinite M200 microplate spectrophotometer (Tecan Group Ltd., Männedorf, Switzerland). The growth inhibition rate was calculated using the following equation: Growth inhibition rate $(\%)=\left(1-\mathrm{OD}_{\text {Sample }} / \mathrm{OD}_{\text {Control }}\right) \times 100$. The half maximal inhibitory concentration $\left(\mathrm{IC}_{50}\right)$ value was calculated using the least-squares method. The $\mathrm{IC}_{50}$ values and nonlinear regression graph were calculated using the GraphPad Prism $^{\circledR}$ (version 5.0; GraphPad Software, Inc., La Jolla, CA, USA) by plotting the log concentration of the cisplatin versus the growth inhibition rate of cells.

Determination of apoptosis. Cellular apoptosis was evaluated using FITC Annexin V/propidium iodide (PI; BD Biosciences) double staining followed by flow cytometric analysis. Cells were treated with 0,5 or $10 \mathrm{mg} / 1$ cisplatin for $24 \mathrm{~h}$. Subsequently, cells were collected and resuspended in $100 \mu \mathrm{l}$ binding buffer containing $5 \mu \mathrm{l}$ Annexin V-FITC and $5 \mu \mathrm{l}$ PI. After 15 min incubation in darkness at room temperature $\left(20-25^{\circ} \mathrm{C}\right)$, a further $400 \mu \mathrm{l}$ of binding buffer was added to the cell suspension and the samples were analyzed by a FACScan flow cytometer (BD Biosciences).

Western blotting analysis. Total protein was extracted from cells using radioimmunoprecipitation assay lysis buffer (Cell Signaling Technology, Inc.) and the protein concentration was measured using BCA Protein Assay kit, according to manufacturer's instructions (Pierce Biotechnology, Inc., Rockford, IL, USA). Equal quantities of protein extract were separated by 10\% SDS-PAGE (Sigma-Aldrich). The gel was run for $20 \mathrm{~min}$ at $80 \mathrm{~V}$ followed by $100 \mathrm{~min}$ at $120 \mathrm{~V}$. Proteins were transferred to a polyvinylidene fluoride or nitrocellulose membrane (EMD Millipore, Billerica, MA, USA). Membranes were blocked with $5 \%$ w/v non-fat dry milk (Sigma-Aldrich) dissolved in Tris-buffered saline plus 0.1\% Tween-20 (TBS-T; $\mathrm{pH}$ 8.3; Sigma-Aldrich) and probed with primary antibodies at $4^{\circ} \mathrm{C}$ overnight. After washing with TBS-T, membranes were incubated with HRP-labeled secondary antibodies for 1-2 $\mathrm{h}$ at room temperature. Immunobands were detected using an enhanced chemiluminescence kit, according to manufacturer's instructions (KPL, Inc., Gaithersburg, MD, USA). The densitometric values of target proteins were analyzed by Quantity One (version 4.62; Bio-Rad Laboratories, Inc., Hercules, CA, USA) or ImageJ (version 1.48; National Institutes of Health, Bethesda, MD, USA) software.

DAPI staining and cell counting. Cells were fixed with $4 \%$ paraformaldehyde (PFA; Sigma-Aldrich) for $15 \mathrm{~min}$, permeabilized in 0.1\% Triton-X100 (Sigma-Aldrich) for $15 \mathrm{~min}$, and stained with DAPI ( $1 \mu \mathrm{g} / \mathrm{ml}$; Sigma-Aldrich) for $5 \mathrm{~min}$ in the dark. After washing with PBS, cell samples were imaged using an IX51 fluorescent microscope (Olympus Corporation, Tokyo, Japan) at x100 magnification. Three fields were randomly captured from each sample and the mean number of DAPI-positive cells was calculated.

Immunocytochemical analysis. Cells were fixed with 4\% PFA for $20 \mathrm{~min}$. After washing with PBS, cells were treated with PBS containing $0.5 \%$ Triton-20 (Sigma-Aldrich) for $10 \mathrm{~min}$. Cell samples were blocked with PBS supplemented with $4 \%$ bovine serum albumin (Sigma-Aldrich) for $1 \mathrm{~h}$ at room temperature and probed with primary antibodies at $4^{\circ} \mathrm{C}$ overnight or at $37^{\circ} \mathrm{C}$ for $3 \mathrm{~h}$. After PBS washing, samples were 
$\mathbf{A}$
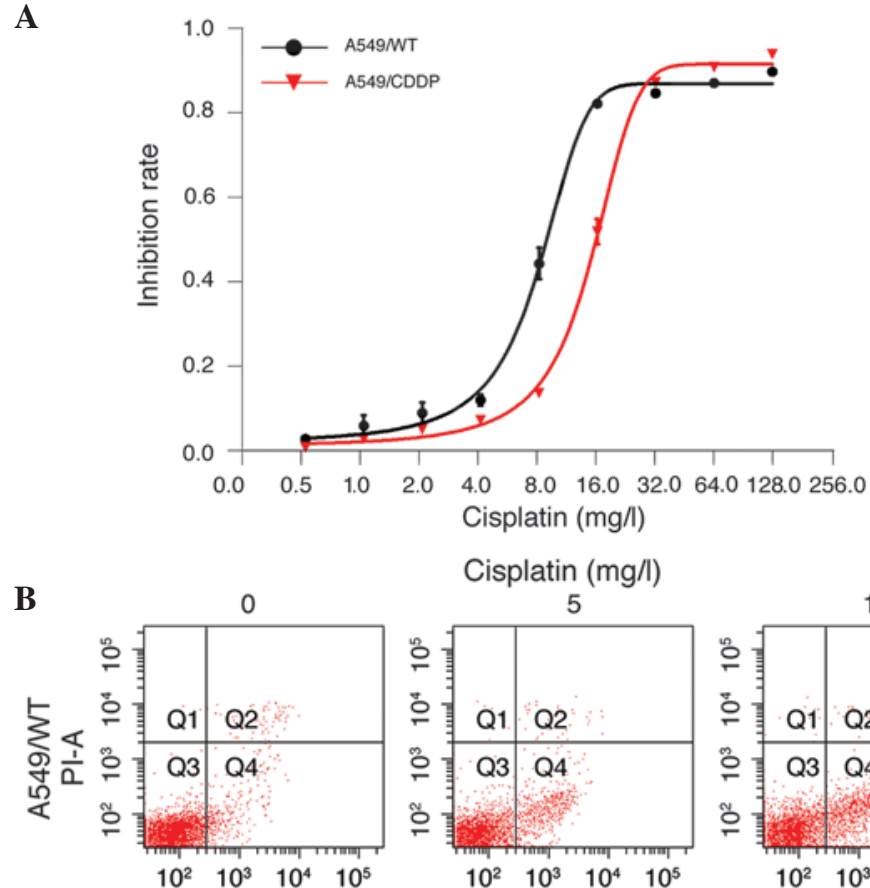

Cisplatin (mg/l)
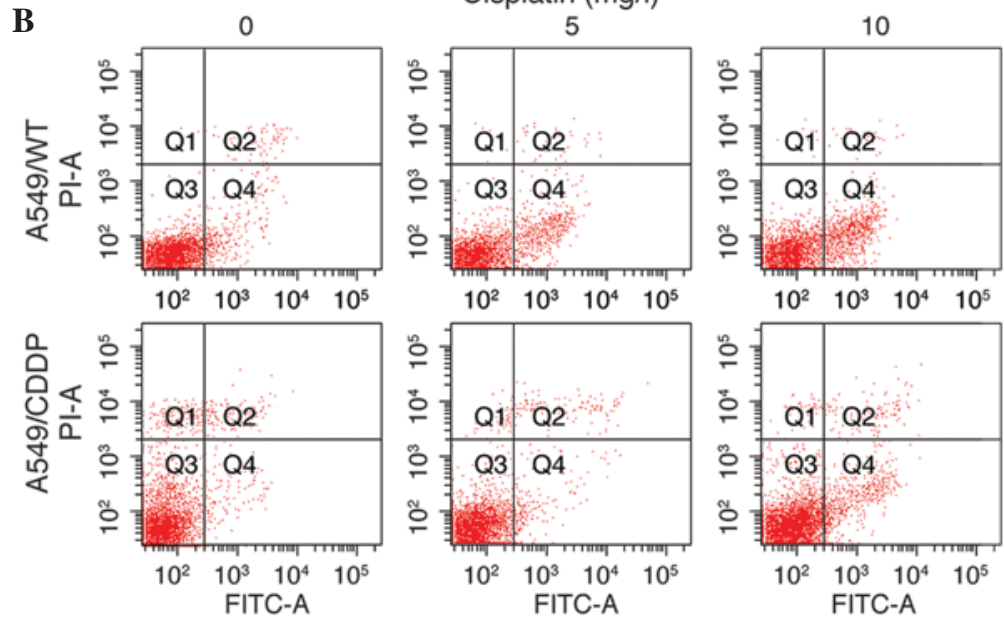

Figure 1. Cisplatin induces differential growth inhibition and apoptosis in A549/WT and A549/CDDP cells. (A) Cells were treated with different concentrations of cisplatin for $48 \mathrm{~h}$. The cell proliferation capacity was determined using MTS assay. Data are presented as mean \pm standard deviation. (B) Cells were incubated with 0,5 or $10 \mathrm{mg} / 1$ cisplatin for $24 \mathrm{~h}$. Apoptotic cell death was evaluated by Annexin V/PI double staining followed with flow cytometric analysis. A549/WT, wild-type A549 cells; A549/CDDP, cisplatin-resistant A549 cells; PI, propidum iodide; FITC, fluorescein isothiocyanate.

incubated with FITC-labeled secondary antibody for $1 \mathrm{~h}$ at $37^{\circ} \mathrm{C}$. The nuclei were counterstained with $5 \mu \mathrm{g} / \mathrm{ml}$ DAPI and the samples were visualized using confocal laser scanning microscopy (Leica TCS SP5II; Leica Microsystems GmbH, Wetzlar, Germany).

RNA interference. To knock down $\beta$-catenin expression, A549 cells were seeded onto six-well plates at a density of $1 \times 10^{5}$ cells/well and maintained in $500 \mu 1$ antibiotic-free culture medium. After $24 \mathrm{~h}$, Lipofectamine 2000 and $33 \mathrm{nM}$ siRNA diluted in $250 \mu 1$ serum- and antibiotic-free culture medium were added to the cell culture. The culture medium was replaced with fresh medium 4-6 $\mathrm{h}$ after transfection. The sequences of siRNAs targeting $\beta$-catenin were as follows: Sense, 5'-GGACACAGCAGCAAUUUGU-3' and anti-sense, 5'-ACAAAUUGCUGCUGUCCTT-3'. Control cells were transfected with negative control siRNA with the following sequences: Sense, 5'-UUCUCCGAACGUGUCACGUTT-3' and anti-sense, 5'-ACGUGACACGUUCGGAGAATT-3'.

Reverse transcription-quantitative polymerase chain reaction $(R T-q P C R)$. Total RNA was extracted using an RNeasy Mini kit, according to the manufacturer's instructions (TianGen Biotech Co., Ltd.). Total RNA ( $2 \mu \mathrm{l})$ was reverse transcribed in a 20- $\mu 1$ reaction system using a Quant Reverse Transcriptase kit (TianGen Biotech Co., Ltd.). qPCR was performed using a 7500 Real-Time PCR system (Thermo Fisher Scientific, Inc.) and a SuperReal PreMix (SYBR Green) kit (TianGen Biotech Co., Ltd.). Primers used for qPCR amplification were as follows: Bcl-xl, forward, 5'-CCTGAATGACCACCTAGA GCCTT-3' and reverse, 5'-TCATGCCCGTCAGGAACCAG-3'; 18S rRNA, forward, 5'-GTAACCCGTTGAACCCCATT-3' and reverse, 5'-CCATCCAATCGGTAGTAGCG-3'. The cycling conditions used were as follows: Pre-denaturation at $94^{\circ} \mathrm{C}$ for $2 \mathrm{~min}$; denaturation at $94^{\circ} \mathrm{C}$ for $15 \mathrm{sec}$; annealing at $55^{\circ} \mathrm{C}$ for $20 \mathrm{sec}$; extension at $68^{\circ} \mathrm{C}$ for $35 \mathrm{sec}$. A total of 40 cycles were performed. The relative expression of Bcl-xl was normalized to $18 \mathrm{~S}$ rRNA and was calculated using the $2^{-\triangle \Delta C q}$ method (12).

Statistical analysis. Data were calculated from three independent experiments and are presented as means \pm standard deviation. Data were analyzed using SPSS software (version 19.0; IBM SPSS, Armonk, NY, USA). Statistical significance was assessed using Student's t-test, Wilcoxon rank-sum test and one-way analysis of variance (ANOVA). Bonferroni correction and Fisher's Least Significant Difference test were performed following one-way ANOVA. $\mathrm{P}<0.05$ indicated a statistically significant difference. Figures were constructed using GraphPad Prism (version 5.0; GraphPad Software, Inc., La Jolla, CA, USA). 
A

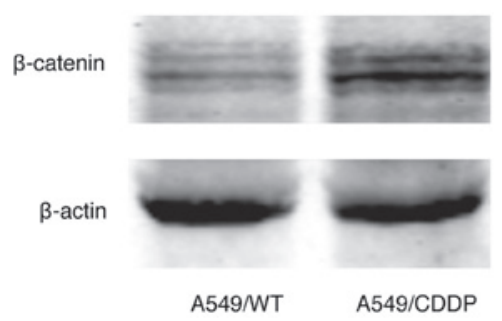

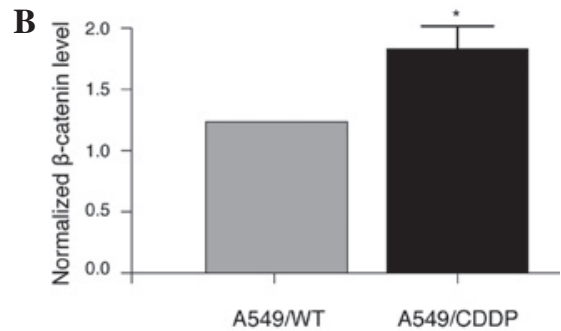

Figure 2. $\beta$-catenin protein expression in A549/WT and A549/CDDP cells. (A) The protein levels of $\beta$-catenin were analyzed by western blotting. $\beta$-actin was used as an internal control. (B) The relative protein level of $\beta$-catenin was calculated from three independent experiments. "P<0.05. Data are presented as mean \pm standard deviation. A549/WT, wild-type A549 cells; A549/CDDP, cisplatin-resistant A549 cells.

A

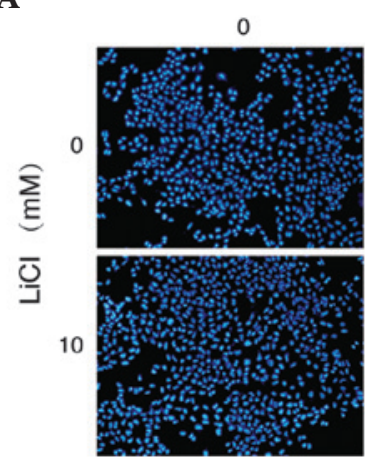

B

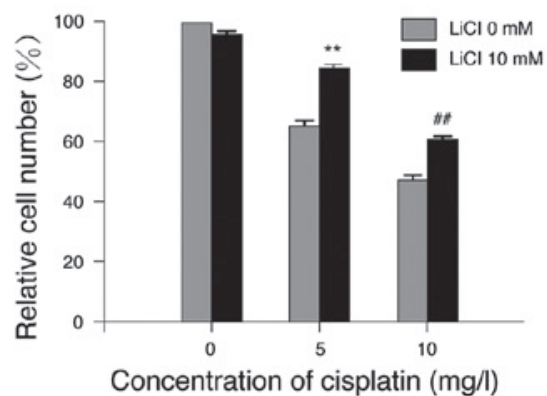

Concentration of cisplatin (mg/l)
Cisplatin (mg/l)
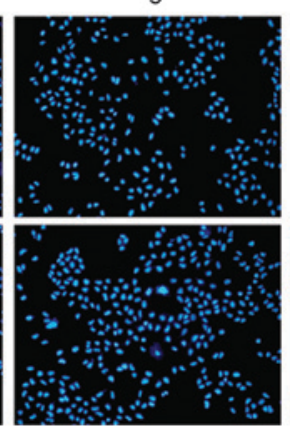

10
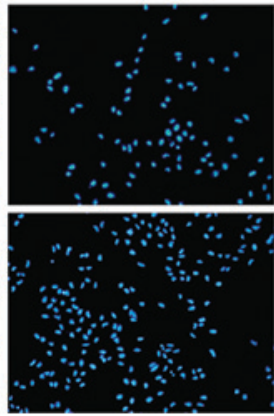

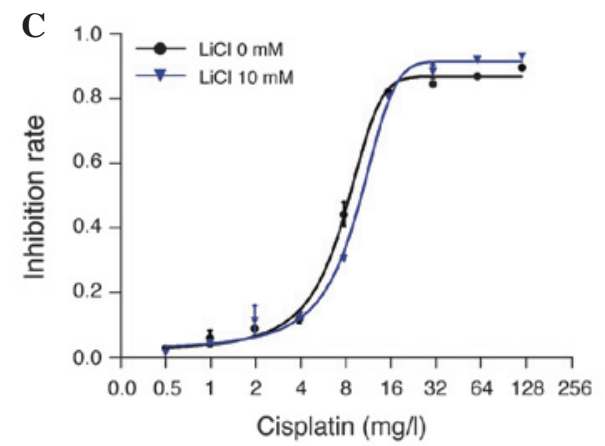

Cisplatin (mg/l)
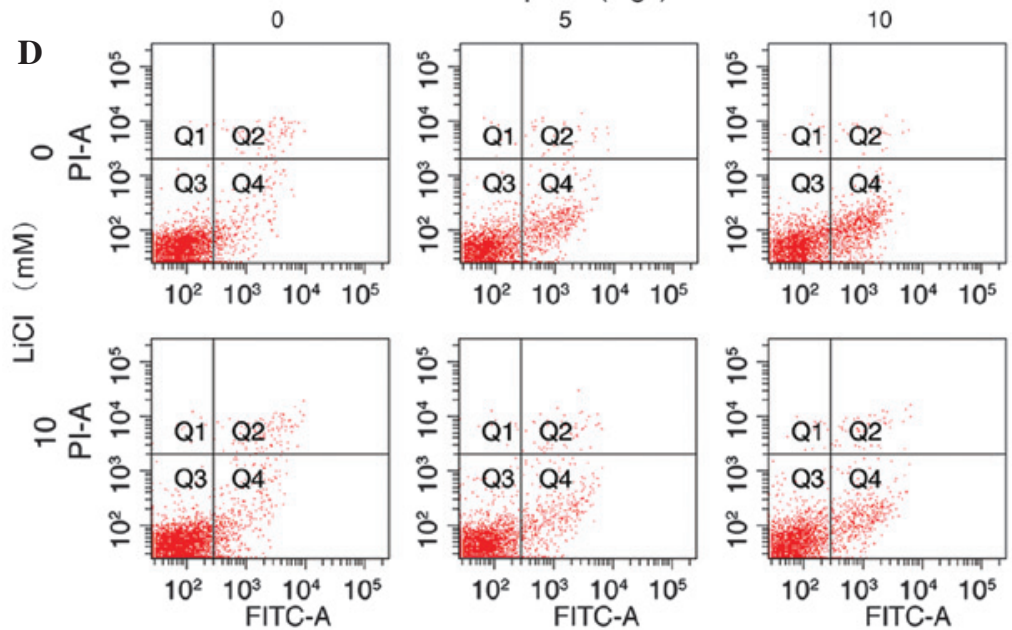

Figure 3. $\mathrm{LiCl}$ reduced the sensitivity of A549/WT cells to cisplatin treatment. Cells were treated with $5 \mathrm{or} 10 \mathrm{mg} / 1$ cisplatin in the presence or absence of $10 \mathrm{mM} \mathrm{LiCl}$ for $24 \mathrm{~h}$. (A) Cells were subsequently stained with DAPI to reveal cell viability (magnification, x100). (B) The relative cell number was determined by normalization to the cell number prior to drug treatment and calculated from three independent experiments. ${ }^{* *} \mathrm{P}<0.01 \mathrm{vs} .5 \mathrm{mg} / \mathrm{l} \mathrm{cisplatin}$ alone; ${ }^{* \#} \mathrm{P}<0.01$ vs. $10 \mathrm{mg} / \mathrm{l}$ cisplatin alone. (C) Cells were treated with increasing concentrations of cisplatin in the presence or absence of $10 \mathrm{mM} \mathrm{LiCl}$ for $48 \mathrm{~h}$ and the cell proliferation capacity was determined using MTS assay. Data are presented as mean \pm standard deviation. (D) Cells were incubated with 0,5 or $10 \mathrm{mg} / 1$ cisplatin in the presence or absence of $10 \mathrm{mM} \mathrm{LiCl}$ for $24 \mathrm{~h}$. Apoptotic cell death was evaluated by Annexin V/PI double staining followed by flow cytometric analysis. LiCl, lithium chloride; PI, propidum iodide; FITC, fluorescein isothiocyanate. 
A

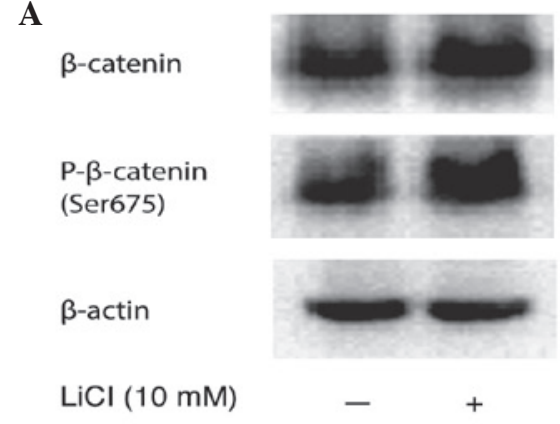

$\mathbf{C}$

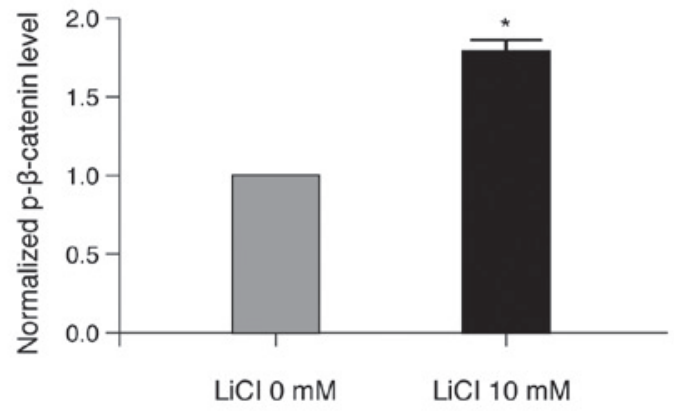

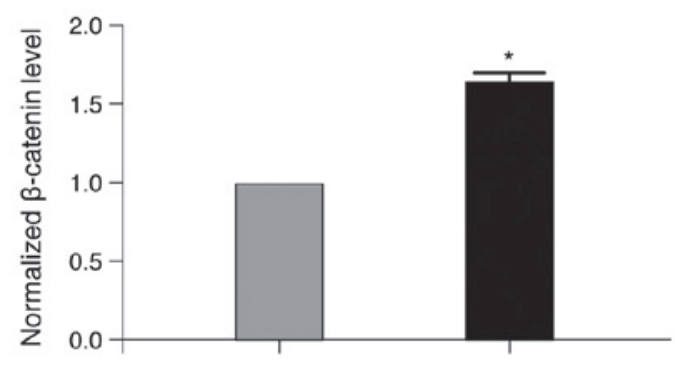

LiCl 0 mM L LiCl $10 \mathrm{mM}$

D $\beta$-catenin

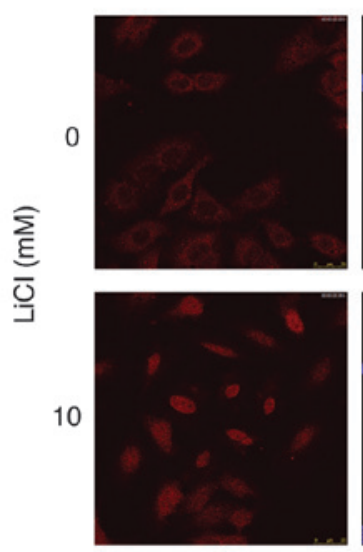

Nuclear

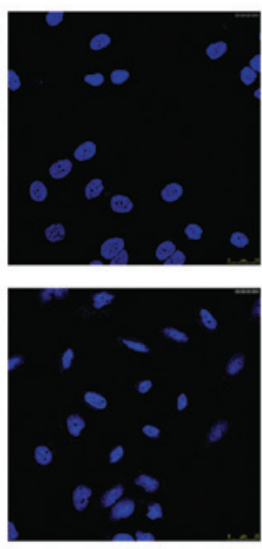

Merged

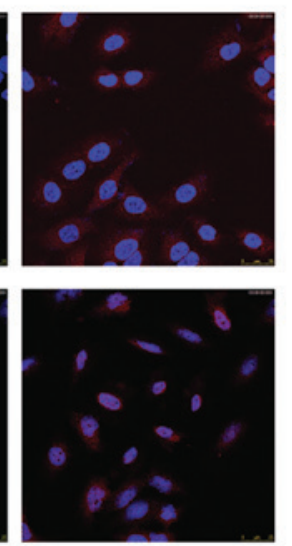

Figure 4. LiCl promotes cisplatin resistance in A549/WT cells by activating Wnt/ $\beta$-catenin signaling. (A) A549/WT cells were treated with or without $10 \mathrm{mM}$ $\mathrm{LiCl}$ for $24 \mathrm{~h}$. The protein expression of $\beta$-catenin and $\mathrm{p}-\beta$-catenin was examined by western blotting. $\beta$-actin was used as an internal control. (B) The relative protein levels of $\beta$-catenin and $(C) p-\beta$-catenin were calculated from three independent experiments. ${ }^{*} \mathrm{P}<0.05$. Data are presented as mean \pm standard deviation. (D) Cells were stained with anti- $\beta$-catenin antibody (red) and nuclei were counterstained with DAPI (blue). Samples were examined using confocal laser scanning microscopy (magnification, $\mathrm{x} 1,000)$. LiCl, lithium chloride; $\mathrm{p}$ - $\beta$-catenin. phosphorylated- $\beta$-catenin.

\section{Results}

$\beta$-catenin expression is increased in A549/CDDP cells. The current study initially determined the sensitivity of human lung adenocarcinoma A549/WT and A549/CDDP cells to different concentrations of cisplatin. An MTS assay demonstrated that cisplatin dose-dependently inhibited the proliferation of A549/WT and A549/CDDP cells; however A549/WT cells were more sensitive to cisplatin exposure. The $\mathrm{IC}_{50}$ value of A549/CDDP cells was two-fold higher than that of A549/WT cells $(14.67 \pm 0.66$ vs. $7.87 \pm 0.57 \mathrm{mg} / \mathrm{l} ; \mathrm{n}=3$; Fig. $1 \mathrm{~A})$. In addition, 5 and $10 \mathrm{mg} / \mathrm{l}$ cisplatin treatment induced apparent apoptosis in A549/WT and A549/CDDP cells, with an increased number of apoptotic cells among A549/WT cells as compared with A549/CDDP cells (Fig. 1B). To investigate the potential role of Wnt $/ \beta$-catenin signaling in cisplatin resistance, the protein expression of $\beta$-catenin in A549/WT and A549/CDDP cells was determined by immunoblotting. As demonstrated in Fig. 2, a significant upregulation of $\beta$-catenin was detected in A549/CDDP cells compared with A549/WT cells $(\mathrm{P}<0.05)$, suggesting that $\beta$-catenin may participate in the cisplatin resistance of lung adenocarcinoma cells.

LiCl reduces the sensitivity of A549/WT cells to cisplatin. $\mathrm{LiCl}$ has previously been demonstrated to confer chemotherapy resistance in several tumor cell types, such as hepatoblastoma (13), ovarian carcinoma (14) and A549 lung cancer cells (8). In the current study, treatment of A549/WT cells with 5 or $10 \mathrm{mg} / \mathrm{l}$ cisplatin resulted in a marked loss of cell viability, which was abolished by treatment with $10 \mathrm{mM} \mathrm{LiCl}(\mathrm{P}<0.01$ compared with cisplatin treatment alone; Fig. $3 \mathrm{~A}$ and B). Furthermore, $10 \mathrm{mM} \mathrm{LiCl}$ reduced the sensitivity of A549/WT cells to different concentrations of cisplatin. The $\mathrm{IC}_{50}$ value of the $\mathrm{LiCl}$ plus cisplatin treatment group was elevated compared with that of cisplatin treatment alone $(9.79 \pm 0.76$ vs. $7.87 \pm 0.57 \mathrm{mg} / \mathrm{l}$; $\mathrm{n}=3$; Fig. $3 \mathrm{C}$ ). In addition, $\mathrm{LiCl}$ markedly reduced cellular apoptosis induced by cisplatin (Fig. 3D). These results indicate that $\mathrm{LiCl}$ reduced the sensitivity of A549/WT cells to cisplatin, suggesting that $\mathrm{LiCl}$-conferred drug resistance may be a general phenomenon in cancer cells.

LiCl treatment activates Wnt/ $\beta$-catenin signaling in A549/WT cells. To assess the molecular mechanism by which $\mathrm{LiCl}$ promoted cisplatin resistance in A549/WT cells, the protein expression level of total and $p-\beta$-catenin in LiCl-treated A549/WT cells was determined. As demonstrated in Fig. 4A-C, $\mathrm{LiCl}$ significantly increased $\beta$-catenin and $\mathrm{p}-\beta$-catenin compared with the non-treated controls $(\mathrm{P}<0.05)$. In addition, $\mathrm{LiCl}$ treatment led to nuclear translocation of $\beta$-catenin in A549/WT cells, indicating the activation of $\beta$-catenin signaling (Fig. 4D). These results suggest that activation of $\mathrm{Wnt} / \beta$-catenin signaling may be one of the mechanisms by which $\mathrm{LiCl}$ promotes cisplatin resistance in A549/WT cells. 

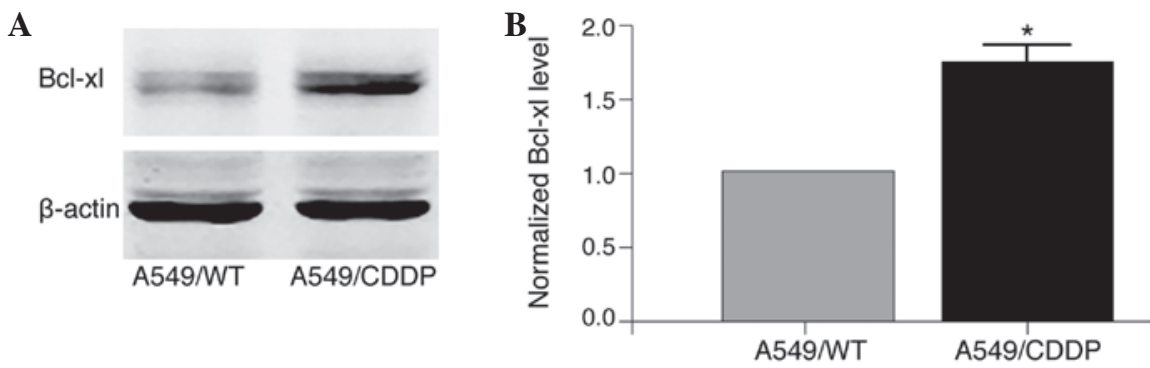

Figure 5. Bcl-xl protein expression in A549/WT and A549/CDDP cells. (A) The protein levels of Bcl-xl were analyzed by western blot analysis. $\beta$-actin was used as an internal control. (B) The relative protein level of Bcl-xl was calculated from three independent experiments. ${ }^{*} \mathrm{P}<0.05$. Data are presented as mean \pm standard deviation. Bcl-xl, B-cell lymphoma-extra large; A549/WT, wild-type A549 cells; A549/CDDP, cisplatin-resistant A549 cells.

\section{A}

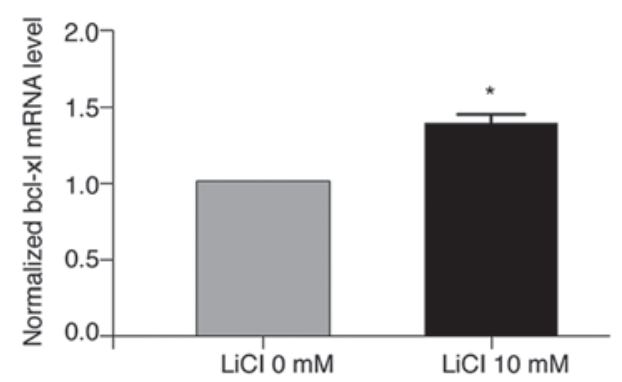

B

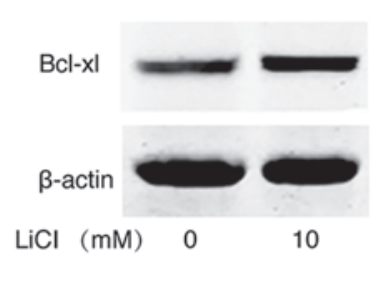

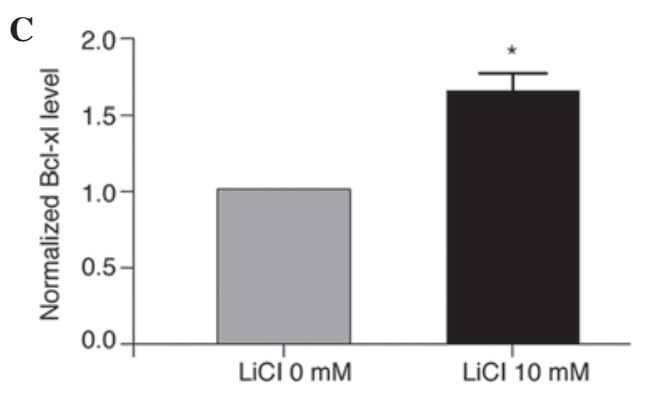

Figure 6. LiCl upregulates Bcl-xl expression in A549/WT cells. (A) A549/WT cells were treated with or without $10 \mathrm{mM} \mathrm{LiCl}$ for $24 \mathrm{~h}$. The mRNA expression of $\mathrm{Bcl}-\mathrm{xl}$ was determined by reverse transcription-quantitative polymerase chain reaction and was normalized $18 \mathrm{~S}$ rRNA. "P<0.05. (B) The protein levels of Bcl-xl were analyzed by western blotting. $\beta$-actin was used as an internal control. (C) The relative protein level of Bcl-xl was calculated from three independent experiments. ${ }^{*} \mathrm{P}<0.05$. Data are presented as mean \pm standard deviation. Bcl-xl, B-cell lymphoma-extra large; $\mathrm{LiCl}$, lithium chloride.

A

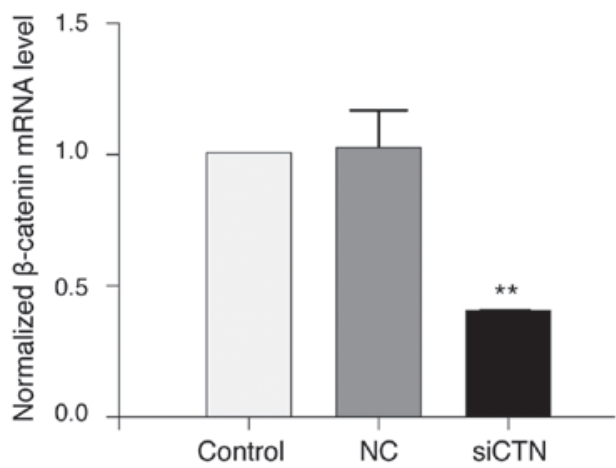

B

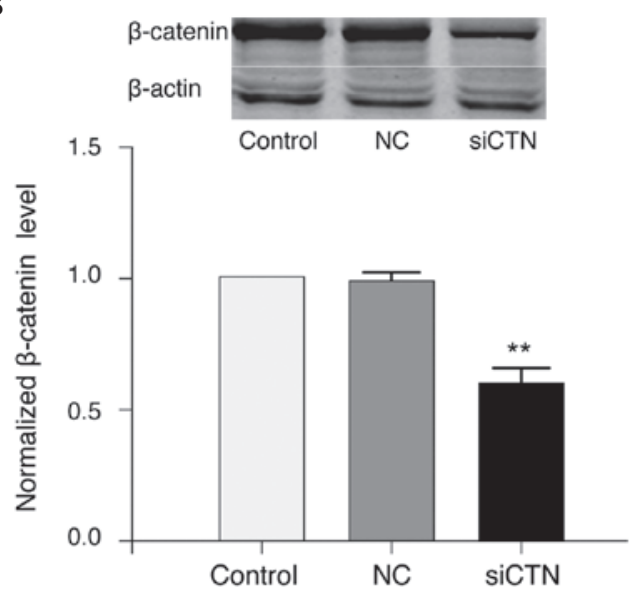

Figure 7. siRNA knockdown of $\beta$-catenin. (A) Cells were transfected with NC siRNA or siCTN. Non-transfected cells were used as controls. The mRNA expression of $\beta$-catenin was determined by reverse transcription-quantitative polymerase chain reaction and was normalized to $18 \mathrm{~S}$ rRNA. ${ }^{* *} \mathrm{P}<0.01 \mathrm{vs}$. NC group. (B) The protein levels of $\beta$-catenin were analyzed by western blotting following siRNA transfection. $\beta$-actin was used as an internal control. The relative protein level of $\beta$-catenin was calculated from three independent experiments. ${ }^{* *} \mathrm{P}<0.01$ vs. NC group. Data are presented as mean \pm standard deviation. $\mathrm{NC}$, negative control; siCTN, small interfering RNA targeting $\beta$-catenin.

LiCl upregulates Bcl-xl expression in A549/WT cells. Bcl-xl is a member of the Bcl-2 protein family and functions as a pro-survival factor, inhibiting cellular apoptosis $(15,16)$. As evasion of apoptosis is the key to drug resistance in cancer treatment, the current study examined the potential involvement of $\mathrm{Bcl}-\mathrm{xl}$ in cisplatin resistance of lung adenocarcinoma cells in the presence and absence of $\mathrm{LiCl}$. The results demonstrated that the protein expression level of Bcl-xl was significantly elevated in A549/CDDP cells compared with A549/WT cells ( $\mathrm{P}<0.05$;
Fig. 5). Furthermore, RT-qPCR analysis revealed that LiCl treatment significantly increased the mRNA expression levels of Bcl-xl in A549/WT cells compared with the non-treated control cells $(\mathrm{P}<0.05$; Fig. 6A). Consistent with the upregulation of Bcl-xl mRNA, western blot analysis demonstrated that treatment with $10 \mathrm{mM} \mathrm{LiCl}$ significantly elevated the protein expression level of Bcl-xl in A549/WT cells ( $\mathrm{P}<0.05$; Fig. 6B and C). Thus, $\mathrm{LiCl}$ treatment of A549/WT cells resulted in increased expression of Bcl-xl at the mRNA and protein level. 

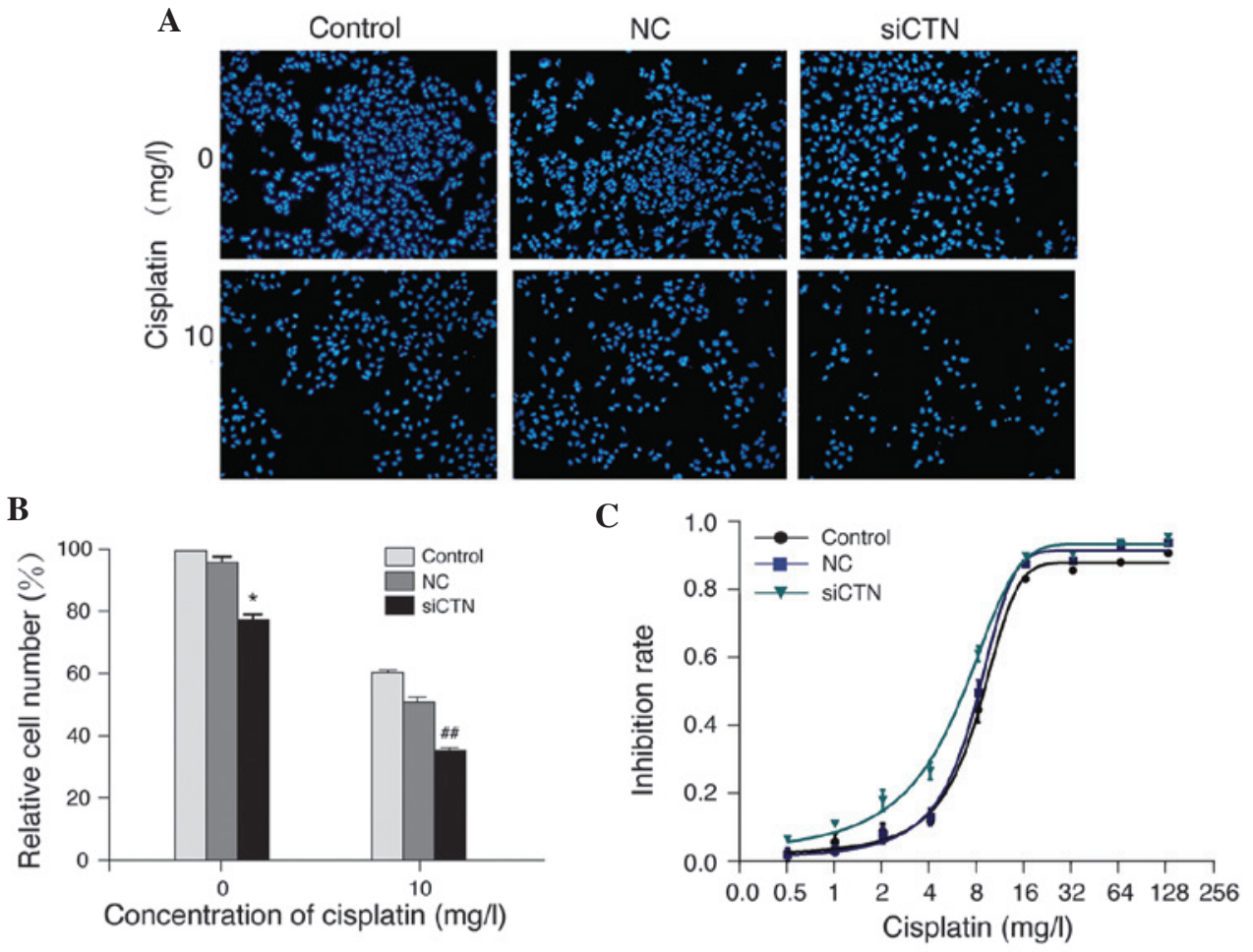

D
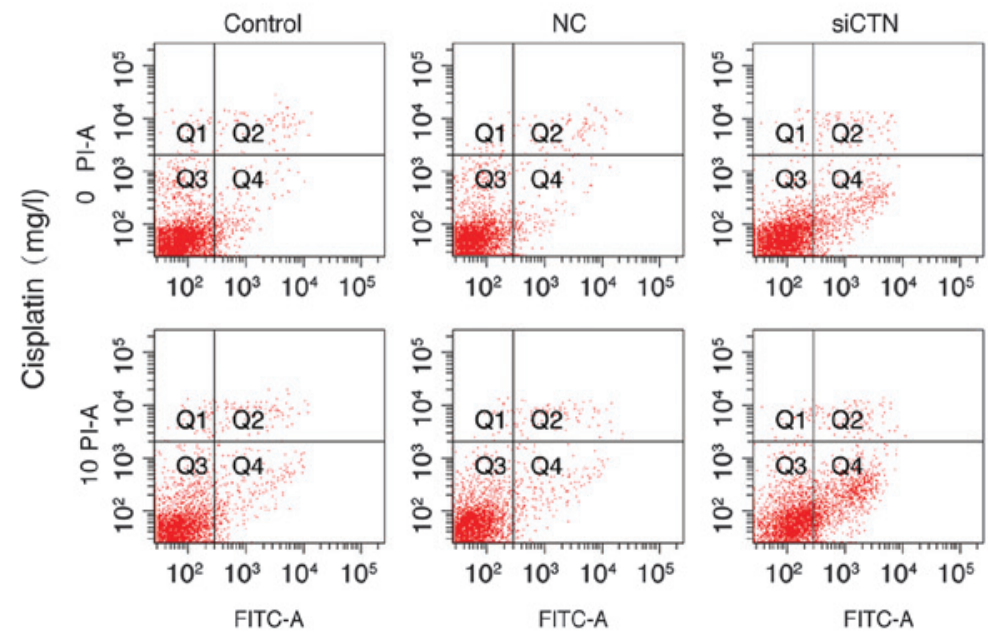

Figure 8. Silencing of $\beta$-catenin increases cisplatin sensitivity of A549/WT cells. (A) Cells were transfected with NC siRNA or siCTN. Non-transfected cells were used as control. Cells were treated with $10 \mathrm{mg} / 1$ cisplatin for $24 \mathrm{~h}$ and subsequently stained with DAPI (magnification, x100). (B) The percentage of cells (normalized to the cell number prior to drug treatment) was calculated from three independent experiments. " $\mathrm{P}<0.05 \mathrm{vs}$. NC cells exposed to $0 \mathrm{mg} / \mathrm{l}$ cisplatin; ${ }^{\# \#} \mathrm{P}<0.01$ vs. NC cells exposed to $10 \mathrm{mg} / \mathrm{l}$ cisplatin. (C) Cells were treated with increasing concentrations of cisplatin for $48 \mathrm{~h}$. Cell proliferation was determined using an MTS assay. (D) Cells were incubated with $10 \mathrm{mg} / \mathrm{l}$ cisplatin for $24 \mathrm{~h}$. Apoptotic cell death was evaluated by Annexin V/PI double staining followed by flow cytometric analysis. NC, negative control; siCTN, siRNA targeting $\beta$-catenin; PI, propidum iodide; FITC, fluorescein isothiocyanate.

A

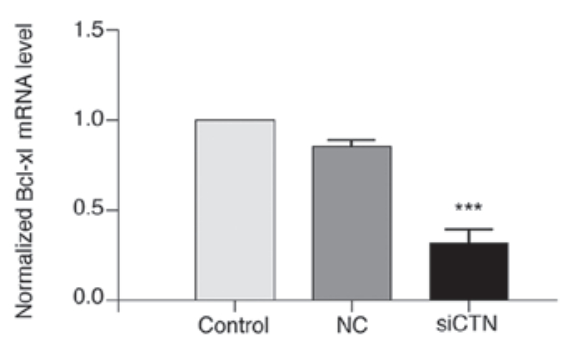

B

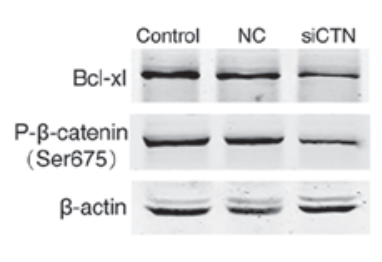

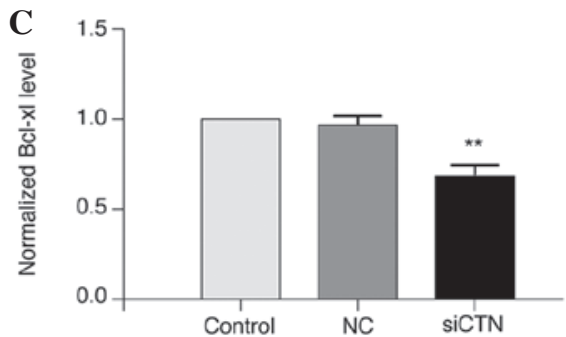

Figure 9. Silencing of $\beta$-catenin downregulates Bcl-xl expression in A549/WT cells. Cells were transfected with NC siRNA or siCTN. Non-transfected cells were used as controls. (A) The mRNA expression of Bcl-xl was determined by reverse transcription-quantitative polymerase chain reaction and was normalized to $18 \mathrm{~S}$ rRNA. ${ }^{* * * *} \mathrm{P}<0.001$ vs. $\mathrm{NC}$ group. (B) The protein levels of $\mathrm{Bcl}-\mathrm{xl}$ and $\mathrm{p}-\beta$-catenin were analyzed by western blotting. $\beta$-actin was used as an internal control. (C) The relative protein level of Bcl-xl was calculated from three independent experiments. ${ }^{* *} \mathrm{P}<0.01$ vs. NC group. Data are presented as mean \pm standard deviation. NC, negative control; siCTN, siRNA targeting $\beta$-catenin; Bcl-xl, B-cell lymphoma-extra large; $p$ - $\beta$-catenin, phosphorylated- $\beta$-catenin. 
Silencing of $\beta$-catenin downregulates Bcl-xl and sensitizes A549/WT cells to cisplatin. In order to explore the potential association between $\mathrm{Bcl}-\mathrm{xl}$ and $\beta$-catenin signaling pathways in cisplatin resistance of lung adenocarcinoma cells, $\beta$-catenin expression was silenced using siRNA in A549/WT cells. Transfection of siRNA targeting $\beta$-catenin efficiently downregulated the mRNA (Fig. 7A) and protein (Fig. 7B) levels of $\beta$-catenin in A549/WT cells compared with negative control siRNA $(\mathrm{P}<0.01)$. Additionally, $\beta$-catenin siRNA significantly inhibited the growth of A549/WT cells $(\mathrm{P}<0.05)$ and caused a further reduction of cisplatin-induced growth inhibition $(\mathrm{P}<0.01$; Fig. 8A and B). Furthermore, silencing of $\beta$-catenin with siRNA decreased the inhibition rate of cisplatin, as demonstrated by MTS assay. The $\mathrm{IC}_{50}$ value of cisplatin was reduced in cells transfected with $\beta$-catenin siRNA ( $\beta$-catenin siRNA, $4.98 \pm 1.37 \mathrm{mg} / \mathrm{l}$; control, $7.87 \pm 0.57 \mathrm{mg} / \mathrm{l}$; negative control, $7.45 \pm 0.49 \mathrm{mg} / \mathrm{l}$; Fig. 8C). Furthermore, $\beta$-catenin siRNA increased cisplatin-induced apoptosis in A549/WT cells (Fig. 8D). In accordance with a previous observation that $\beta$-catenin promoted transcription of $\mathrm{Bcl}-\mathrm{xl}$ (17), the present study observed that silencing of $\beta$-catenin in A549/WT cells significantly decreased the mRNA $(\mathrm{P}<0.001$; Fig. 9A) and protein $(\mathrm{P}<0.01$; Fig. 9B and $\mathrm{C})$ expression of $\mathrm{Bcl}-\mathrm{xl}$ compared with negative control cells. In addition, knockdown of $\beta$-catenin reduced $\beta$-catenin phosphorylation in A549/WT cells (Fig. 9B). These results indicate that silencing of $\beta$-catenin sensitized A549/WT cells to cisplatin and this effect may be mediated by downregulation of Bcl-xl expression.

\section{Discussion}

Cisplatin resistance is a major challenge during lung cancer treatment. The molecular mechanism of cisplatin resistance in lung cancer cells is largely unknown, therefore, there are few efficient strategies to overcome such resistance. The current study revealed the Wnt/ $\beta$-catenin signaling pathway and anti-apoptotic protein Bcl-xl to be involved in cisplatin resistance of human A549 cells. These findings indicate that molecular targeting of $\mathrm{Wnt} / \beta$-catenin signaling may sensitize lung cancer cells to cisplatin.

Platinum derivatives, such as cisplatin, are widely used chemotherapeutic agents during lung cancer treatment, however, their efficiency can be affected by a number of factors (5). Various genes are abnormally expressed in drug resistant cancer cells, such as increased levels of anti-apoptotic genes (such as Bcl-xl, Bcl-2 and Survivin) and reduced levels of pro-apoptotic genes (such as Bax and Bcl-2-associated death promoter) (18). In addition, multiple signaling pathways are activated during cisplatin resistance, including the Wnt/ $\beta$-catenin pathway (8-10). However, the cross-talk that occurs among these signaling pathways and mediators is still unclear.

The Wnt/ $\beta$-catenin signaling pathway has been shown to be an essential signal transduction pathway in tumorigenesis and progression of various types of cancer $(19,20)$. In the present study, a significant upregulation of $\beta$-catenin was observed in A549/CDDP cells compared with A549/WT cells, which is in accordance with a previous observation (8). Furthermore, interference of $\beta$-catenin expression by siRNA suppressed cell growth and increased cisplatin sensitivity in
A549/WT cells. Consistent with the findings of the current study, a previous investigation observed that downregulation of $\beta$-catenin expression reversed resistance to cisplatin in A2780 ovarian cancer cells (21). The same in vivo study demonstrated that silencing of $\beta$-catenin inhibited the progression of ovarian cancer in mice (21). Other studies have proposed the $\mathrm{Wnt} / \beta$-catenin pathway as a potential therapeutic target in hepatocellular carcinoma (HCC) $(22,23)$. These lines of evidence suggest that targeting Wnt/ $\beta$-catenin signaling is a promising strategy for combating cisplatin resistance in lung cancer.

It is widely accepted that defects in the apoptotic pathway contribute to tumor cell survival and resistance to anticancer therapy (18). Therefore, targeting endogenous apoptotic inhibitor proteins, such as the Bcl-2 family, is considered to be a promising strategy for the treatment of cancer and overcoming chemotherapeutic resistance $(16,24)$. Bcl-xl, a member of the Bcl-2 family, is a pro-survival protein that prevents apoptosis by inhibiting the release of cytochrome $c$ from mitochondria $(15,16)$. In the present study, increased expression of Bcl-xl mRNA was detected in A549/CDDP cells and $\mathrm{LiCl}$ significantly elevated the mRNA and protein levels of Bcl-xl in A549/WT cells. Notably, silencing of $\beta$-catenin increased the sensitivity of A549/WT cells to cisplatin and downregulated Bcl-xl expression. These results indicate that Bcl-xl may be a critical target gene of $\mathrm{Wnt} / \beta$-catenin signaling in cisplatin-resistant lung cancer.

$\beta$-catenin is a key component of $\mathrm{Wnt} / \beta$-catenin signaling. Activated $\beta$-catenin translocates into the nucleus and binds to T-cell factors to regulate transcription. Accumulating evidence has suggested that tumor cells depend on $\beta$-catenin for survival and downregulation of $\beta$-catenin results in tumor cell apoptosis, which is associated with reduced levels of Bcl-xl (25). $\beta$-catenin was identified to induce $\mathrm{Bcl}-\mathrm{xl}$ expression in $\mathrm{CD}^{+}$ $\mathrm{T}$ cells, whereas upregulated $\beta$-catenin reduced $\mathrm{Bcl}-\mathrm{xl}$ in cultured HepG2 HCC cells (26). This contradiction may be attributed to the varied responses and signaling mechanisms in different types of cancer cells. In addition, other members of the Bcl-2 protein family, such as Bcl-2, Bax and Bcl-2 homologous antagonist/killer, may also be involved in anticancer drug resistance regulated by Wnt $/ \beta$-catenin signaling.

In summary, the present study demonstrated that A549/CDDP cells expressed high levels of $\beta$-catenin and Bcl-xl, and interference of $\beta$-catenin by siRNA enhanced cisplatin sensitivity in A549/WT cells by downregulation of Bcl-xl. The findings suggest that targeting $\mathrm{Wnt} / \beta$-catenin signaling may be a valuable strategy for overcoming cisplatin resistance in lung cancer. Future studies should investigate the effects of $\beta$-catenin silencing in vivo using animal models of lung cancer.

\section{Acknowledgements}

This study was supported by the Specialized Research Fund for the Doctoral Program of Higher Education (grant no. 20111107110003).

\section{References}

1. Torre LA, Bray F, Siegel RL, Ferlay J, Lortet-Tieulent J, Jemal A: Global cancer statistics, 2012. CA Cancer J Clin 65: 87-108, 2015. 
2. Prokop M: Lung cancer screening: The radiologist's perspective Semin Respir Crit Care Med 35: 91-98, 2014.

3. MacDonagh L, Gray SG, Finn SP, Cuffe S, O'Byrne KJ and Barr MP: The emerging role of microRNAs in resistance to lung cancer treatments. Cancer Treat Rev 41: 160-169, 2015.

4. Dasari S and Tchounwou PB: Cisplatin in cancer therapy: Molecular mechanisms of action. Eur J Pharmacol 740: 364-378, 2014.

5. Wang G, Reed E and Li QQ: Molecular basis of cellular response to cisplatin chemotherapy in non-small cell lung cancer (Review). Oncol Rep 12: 955-965, 2004.

6. Stewart DJ: Wnt signaling pathway in non-small cell lung cancer J Natl Cancer Inst 106: djt356, 2014.

7. Xia Y, He Z, Liu B, Wang P and Chen Y: Downregulation of Meg3 enhances cisplatin resistance of lung cancer cells through activation of the WNT/ $\beta$-catenin signaling pathway. Mol Med Rep 12: 4530-4537, 2015 .

8. Teng Y, Wang X, Wang Y and Ma D: Wnt/beta-catenin signaling regulates cancer stem cells in lung cancer A549 cells. Biochem Biophys Res Commun 392: 373-379, 2010.

9. Xie C, Pan Y, Hao F, Gao Y, Liu Z, Zhang X, Xie L, Jiang G, Li Q and Wang E: C-Myc participates in $\beta$-catenin-mediated drug resistance in A549/DDP lung adenocarcinoma cells. APMIS 122: 1251-1258, 2014.

10. Gao Y, Liu Z, Zhang X, He J, Pan Y,Hao F, Xie L, Li Q, Qiu X and Wang E: Inhibition of cytoplasmic GSK-3 $\beta$ increases cisplatin resistance through activation of $\mathrm{Wnt} / \beta$-catenin signaling in A549/DDP cells. Cancer Lett 336: 231-239, 2013.

11. Ding Y, Shen S, Lino AC, Curotto de Lafaille MA and Lafaille JJ: Beta-catenin stabilization extends regulatory T cell survival and induces anergy in nonregulatory T cells. Nat Med 14: 162-169, 2008.

12. Livak KJ and Schmittgen TD: Analysis of relative gene expression data using real-time quantitative PCR and the 2(-Delta Delta C(T)) Method. Methods 25: 402-408, 2001.

13. Beurel E, Kornprobst M, Blivet-Van Eggelpoel MJ, Ruiz-Ruiz C, Cadoret A, Capeau J and Desbois-Mouthon C: GSK-3beta inhibition by lithium confers resistance to chemotherapy-induced apoptosis through the repression of CD95 (Fas/APO-1) expression. Exp Cell Res 300: 354-364, 2004.
14. Cai G, Wang J, Xin X, Ke Z and Luo J: Phosphorylation of glycogen synthase kinase-3 beta at serine 9 confers cisplatin resistance in ovarian cancer cells. Int J Oncol 31: 657-662, 2007.

15. Volkmann N, Marassi FM, Newmeyer DD and Hanein D: The rheostat in the membrane: BCL-2 family proteins and apoptosis. Cell Death Differ 21: 206-215, 2014.

16. Xiong S, Mu T, Wang G and Jiang X: Mitochondria-mediated apoptosis in mammals. Protein Cell 5: 737-749, 2014.

17. Xie H, Huang Z, Sadim MS and Sun Z: Stabilized beta-catenin extends thymocyte survival by up-regulating Bcl-xL. J Immunol 175: 7981-7988, 2005.

18. Kang $\mathrm{MH}$ and Reynolds CP: Bcl-2 inhibitors: Targeting mitochondrial apoptotic pathways in cancer therapy. Clin Cancer Res 15: 1126-1132, 2009.

19. Arend RC, Londono-Joshi AI, Straughn JM, Jr. and Buchsbaum DJ: The Wnt/ $\beta$-catenin pathway in ovarian cancer: A review. Gynecol Oncol 131: 772-779, 2013

20. Holland JD, Klaus A, Garratt AN and Birchmeier W: Wnt signaling in stem and cancer stem cells. Curr Opin Cell Biol 25: 254-264, 2013.

21. Zhao H, Wei W, Sun Y, Gao J, Wang Q and Zheng J: Interference with the expression of $\beta$-catenin reverses cisplatin resistance in A2780/DDP cells and inhibits the progression of ovarian cancer in mouse model. DNA Cell Biol 34: 55-62, 2015.

22. Dahmani R, Just PA and Perret C: The Wnt/ $\beta$-catenin pathway as a therapeutic target in human hepatocellular carcinoma. Clin Res Hepatol Gastroenterol 35: 709-713, 2011.

23. Yeh CT, Rao YK, Ye M, Wu WS, Chang TC, Wang LS, Wu CH, Wu AT and Tzeng YM: Preclinical evaluation of destruxin B as a novel Wnt signaling target suppressing proliferation and metastasis of colorectal cancer using non-invasive bioluminescence imaging. Toxicol Appl Pharmacol 261: 31-41, 2012.

24. Kamal A, Faazil S and Malik MS: Apoptosis-inducing agents: A patent review (2010-2013). Expert Opin Ther Pat 24: 339-354, 2014.

25. Choi PS, Li Y and Felsher DW: Addiction to multiple oncogenes can be exploited to prevent the emergence of therapeutic resistance. Proc Natl Acad Sci USA 111: E3316-3324, 2014.

26. Li W, Tong H, Huang X, Wang W, Wu H and Lin S: High levels of $\beta$-catenin promote IFN $\gamma$-induced apoptosis in hepatocellular carcinoma cells. Oncol Lett 4: 1092-1096, 2012. 